\title{
Ottawa Ankle Rules in primary care - awareness, importance and use by family physicians
}

\author{
HÜSNA ÇEVIK ${ }^{1, A-G}$, HÜSEYIN BILGEHAN ÇEVIK ${ }^{2, A, c, E, F}$, ARZU UZUNER ${ }^{3, c, E}$ \\ ORCID ID: 0000-0003-1945-3715
}

${ }^{1}$ Family Medicine Department, Ankara University Medical School, Ankara, Turkey

${ }^{2}$ Orthopaedics and Traumatology Department, Dışkapı Yıldırım Beyazıt Training and Research Hospital, Ankara, Turkey

${ }^{3}$ Family Medicine Department, Marmara University Pendik Training and Research Hospital, İstanbul, Turkey

A - Study Design, B - Data Collection, C - Statistical Analysis, D - Data Interpretation, E - Manuscript Preparation, F - Literature Search, G - Funds Collection

Summary Background. With the implementation by family physicians of the Ottawa Ankle Rules (OAR), which are clinical decision rules for ankle trauma, referral rates to secondary hospitals could be decreased and the majority of these problems could be resolved for patients in primary care.

Objectives. The aim of this study was to determine the awareness levels of OAR among primary care physicians, and to show the importance of OAR.

Material and methods. This research was planned as a volunteer-based, descriptive survey study conducted with practicing family physicians. An online questionnaire was delivered to participants through e-mail groups of family medicine associations over 3 months. Results. A total of 456 physicians responded to the questionnaire, comprising 307 (67.3\%) females, and $149(32.7 \%)$ males. OAR were known and used by $10.7 \%$ of the respondents. Most physicians thought OAR is appropriate for evidence-based medicine (94.5\%), useful to clarify X-ray requirements (95\%) and to reduce the cost of healthcare $(94.3 \%)$.

Conclusions. As the healthcare system requires primary care physicians to deal with traumatic ankle/foot injuries, there should be a greater awareness of the OAR, with information and training given to all primary care physicians.

Key words: primary health care, algorithms, ankle fractures.

Çevik H, Çevik HB, Uzuner A. Ottawa Ankle Rules in primary care - awareness, importance and use by family physicians. Fam Med Prim Care Rev 2019; 21(4): 324-328, doi: https://doi.org/10.5114/fmpcr.2019.90160.

\section{Background}

Clinical decision rules enable physicians to make systematic and evidence-based clinical judgements [1-3]. The rate of application of these rules increases according to their academic acceptance, cost-effectiveness, simplicity and algorithmic structure [4].

Research on clinical guidelines suggests that these algorithms for helping to make diagnostic and therapeutic decisions are not sufficiently used by primary care physicians in their daily clinical practice. However, sometimes the inappropriate use of these algorithms leads to ineffectiveness and unnecessary diagnostic tests [5-7].

Various radiography guides have been prepared to avoid misdiagnosed fractures after foot and ankle injuries [8-10]. The Ottawa Ankle Rules (OAR) are one of the most widely used and well-established guides in medical practice to determine the need for radiography [10-12]. OAR is a set of globally accepted rules established by Canadian researchers to clarify the indication of requesting an X-Ray for patients with traumatic foot and ankle injuries [11-15]. Several studies and systematic reviews have shown that OAR has sensitivity of $98-100 \%$ and specificity of $40-48 \%[1,7,10,14,16]$.

The number of emergency medicine physicians will not meet workforce needs for decades, and family physicians will be needed in the workforce [17]. Primary care physicians are often confronted with foot/ankle injuries, although the frequency of these is unknown [13]. Despite the fact that approximately $10-25 \%$ of these patients have fractures, almost all go for a radiographic examination [11, 18-21]. As in many other countries, there are no radiographic imaging facilities in primary care in

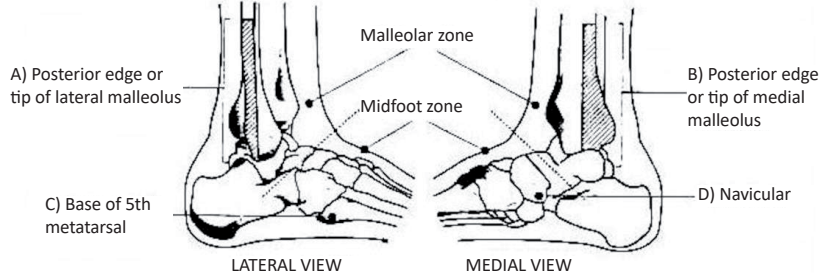

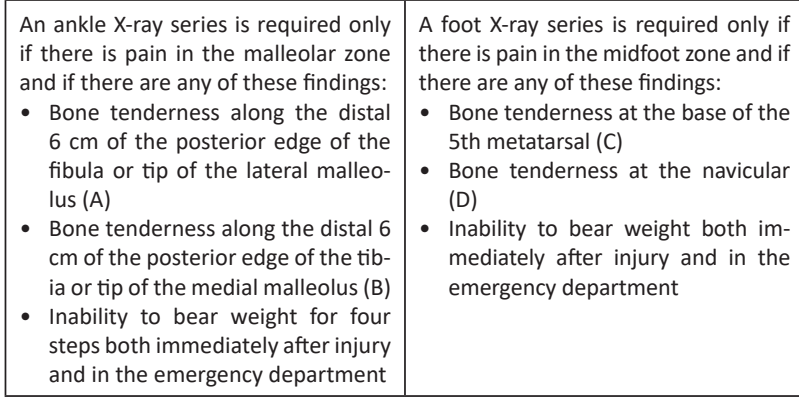

Figure 1. Scheme of the Ottawa Ankle Rules (figure is rearranged)

Turkey. Therefore, patients presenting with traumatic foot/ /ankle injuries to family physicians are referred to hospital emergency departments in Turkey, whereas, whereas if OAR were to be applied, only patients with OAR positivity would be referred for radiography rather than every case $[22,23]$. Consequently, the implementation of OAR to appropriate cases by family physicians may decrease the referral rates to secondary hospitals and may resolve the vast majority of these patient's problems in primary care. 
It has been reported in literature that the use of OAR reduces unnecessary radiography, thereby reducing both exposure of the patient to radiation and the cost burden caused by radiography [24, 25].

However, similar to other clinical decision-making processes, various studies have shown that the awareness and the usage of OAR differ from country to country [26]. It has been reported that the awareness of OAR varies between $21 \%$ and $99 \%$, and usage varies between $33 \%$ and $70 \%$ [26].

\section{Objectives}

No research has been carried out concerning the awareness of OAR in Turkey. However, there is a widespread practice of family medicine in primary care in Turkey. Ankle injuries are also common according to epidemiological data [27, 28]. The purpose of this study was to determine the awareness of OAR among primary care physicians in Turkey.

\section{Material and methods}

There are approximately 26,000 physicians providing primary care services in Turkey (family medicine residents, family medicine specialists, faculty members, general practitioners, contracted family medicine specialty students [CFMS]). This research was planned as a descriptive survey study based on the voluntary participation of physicians who are practicing as a family physician. The scope of the research was constituted by the physicians determined above. Approval for the study was granted by the Clinical Research Ethics Committee of Marmara University Faculty of Medicine (15.09.2017/09.2017.587). The sample size of the study was calculated based on awareness studies of emergency physicians in five countries as 375 physicians with a $95 \%$ confidence interval, $5 \%$ margin of error and $75 \%$ predicted value [26]. Data were gathered through an online survey delivered as an online questionnaire to participants through the e-mail groups of family medicine associations. The study was conducted over 3 months between 10.10.2017-10.01 .2018 , and a total of 456 physicians voluntarily participated in the study. These respondents comprised 307 (67.3\%) females and 149 (32.7\%) males.

The questionnaire was prepared based on studies about OAR essentials and on an awareness study conducted in five countries [10-12, 24, 26]. To avoid preconceptions, the word "Ottawa" was not used in the title and it was not stated until the third question. The first item of the survey was related to the sociodemographic characteristics of participants. In the second question, participants were asked about their attitudes to requesting an X-ray for a patient with a traumatic foot/ankle injury when given OAR items individually. In the third question, they were asked about their awareness of OAR. Before proceeding to the fourth question, a brief description and illustration of OAR (Figure 1) were given. Finally, the participants were questioned about the benefits of these rules in contributing to the practice of medicine.

IBM SPSS Statistics version 18.0 software was used for statistical analysis. The Mann-Whitney $U$ test was used to compare descriptive statistical methods, and quantitative non-parametric data for two groups. The Kruskal-Wallis test was used for the comparison of more than two groups. The Fisher-Freeman-Halton test was applied in the comparisons of qualitative data. A value of $p<0.05$ was accepted as statistically significant.

\section{Results}

The participating physicians ranged in age from 24 to 57 years (median: 30 years), with an average of $31.76 \pm 6.96$ years. The mean time since graduation was $7.28 \pm 6.87$ years (range,
1-33 years, median: 5). For the family medicine (FM) specialists, the time since graduation from the residency programme was mean $4.73 \pm 6.57$ years (range, new specialist -27 years (median: 1)).

\begin{tabular}{|l|l|}
\hline \multicolumn{2}{|l|}{ Table 1. Occupations and workplaces of the study participants } \\
\hline Title & $n(\%)$ \\
\hline Family Medicine Resident & $226(49.5)$ \\
\hline General Practitioner & $103(22.6)$ \\
\hline Family Medicine Specialist & $91(20.0)$ \\
\hline CFMS & $25(5.5)$ \\
\hline Professor of FM & $5(1.1)$ \\
\hline Assistant Professor of FM & $4(0.9)$ \\
\hline Associate Professor of FM & $2(0.4)$ \\
\hline Workplace & $n(\%)$ \\
\hline $\begin{array}{l}\text { Teaching Hospital (University Hospital or Training } \\
\text { and Research Hospital) }\end{array}$ & $254(55.7)$ \\
\hline Family and Community Health Centre & $164(36.0)$ \\
\hline State Hospital & $30(6.6)$ \\
\hline Private Hospital/Clinic & $8(1.7)$ \\
\hline
\end{tabular}

All the conditions given in Table 2 are items of OAR. A direct $X$-ray should be requested if one or more of these clinical conditions are present on ankle examination.

The number of items selected as a clinical condition requiring an X-ray was mean $3.25 \pm 1.78$ (range, 1-5) (Table 2).

\begin{tabular}{|c|c|}
\hline Clinical findings & $n(\%)$ \\
\hline $\begin{array}{l}\text { Bone tenderness along the distal } 6 \mathrm{~cm} \text { of the poste- } \\
\text { rior edge of the tibia or tip of the medial malleolus }\end{array}$ & $269(59.0)$ \\
\hline $\begin{array}{l}\text { Bone tenderness along the distal } 6 \mathrm{~cm} \text { of the poste- } \\
\text { rior edge of the fibula or tip of the lateral malleolus }\end{array}$ & $268(58.8)$ \\
\hline Bone tenderness on the navicular bone & $255(55.9)$ \\
\hline Bone tenderness on the base of the fifth metatarsal & $269(59.0)$ \\
\hline $\begin{array}{l}\text { Inability to bear weight for four steps both immedi- } \\
\text { ately after injury and in the emergency department }\end{array}$ & $423(92.8)$ \\
\hline
\end{tabular}

* Multiple selections made.

Table 3. Distributions of the number of chosen items according to the status of OAR awareness

\begin{tabular}{|c|c|c|c|c|}
\hline & & \multicolumn{3}{|l|}{ OAR } \\
\hline & & $\begin{array}{l}\text { Aware } \\
(n=89)\end{array}$ & $\begin{array}{l}\text { Unaware } \\
(n=367)\end{array}$ & Total \\
\hline \multirow{5}{*}{$\begin{array}{l}\text { The number of } \\
\text { chosen items for } \\
\text { clinical condi- } \\
\text { tions requiring } \\
\text { an X-ray for } \\
\text { patients with } \\
\text { traumatic ankle } \\
\text { injuries }\end{array}$} & 1 & 28 (31.5\%) & $120(32.7 \%)$ & $148(32.5 \%)$ \\
\hline & 2 & $1(1.1 \%)$ & 27 (7.4\%) & $28(6.1 \%)$ \\
\hline & 3 & 5 (5.6\%) & $44(12.0 \%)$ & 49 (10.8\%) \\
\hline & 4 & $6(6.7 \%)$ & $16(4.4 \%)$ & $22(4.8 \%)$ \\
\hline & 5 & 49 (55.1\%) & $160(43.5 \%)$ & 209 (45.8\%) \\
\hline
\end{tabular}

Of the total participants, 89 (19.5\%) stated that they were aware of OAR, and $367(80.5 \%)$ stated that they were not aware of OAR (Survey Question 3).

Only 49 of the 89 physicians who stated that they were aware of OAR evaluated all the items of OAR given individually in the previous question as an indication for taking an X-ray. They were accepted as physicians who know OAR, and these physicians were evaluated in statistical analyses. 


\begin{tabular}{|c|c|c|c|c|c|}
\hline & \multicolumn{5}{|c|}{ Agreement level } \\
\hline & strongly agree & agree & undecided & disagree & $\begin{array}{l}\text { strongly } \\
\text { disagree }\end{array}$ \\
\hline & $n(\%)$ & $n(\%)$ & $n(\%)$ & $n(\%)$ & $n(\%)$ \\
\hline 1. Reducing the cost of healthcare & $281(61.6)$ & $149(32.7)$ & $18(3.9)$ & $6(1.4)$ & $2(0.4)$ \\
\hline 2. Appropriateness to evidence-based medicine & $282(61.8)$ & $149(32.7)$ & $23(5.1)$ & $2(0.4)$ & $0(0)$ \\
\hline 3. Clarification of X-ray requirement & $269(59.0)$ & $164(36.0)$ & $16(3.5)$ & $7(1.5)$ & $0(0)$ \\
\hline 4. To protect against malpractice & $199(43.6)$ & $142(31.2)$ & $71(15.6)$ & $28(6.1)$ & $16(3.5)$ \\
\hline 5. To protect against patient complaints & $161(35.3)$ & $144(31.6)$ & $76(16.7)$ & $55(12.0)$ & $20(4.4)$ \\
\hline 6. Reduction of unnecessary radiation exposure & $259(56.8)$ & $151(33.1)$ & $32(7.0)$ & $13(2.9)$ & $1(0.2)$ \\
\hline 7. Ease of application & $215(47.1)$ & $199(43.7)$ & $35(7.7)$ & $5(1.1)$ & $2(0.4)$ \\
\hline 8. Clarification of referral criteria & 214 (46.9) & $177(38.8)$ & $47(10.4)$ & $12(2.6)$ & $6(1.3)$ \\
\hline
\end{tabular}

There was no statistically significant difference between the 49 physicians who were aware of OAR and the 160 physicians who were unaware of OAR according to their titles $(p=0.732$; $p>0.05)$ and workplaces $(p=0.883 ; p>0.05)$ in respect of requesting an $X$-ray for $5 / 5$ of the given clinical conditions.

There was no statistically significant difference between being aware of OAR $(n=49)$ and year of graduation $(p=0.786)$, workplace $(p=0.691)$ and title $(p=0.253)$.

The agreement of physicians with the expressions about the benefits of OAR in contributing to the practice of medicine was evaluated with a Likert Scale: strongly disagree (0), disagree (1), undecided (2), agree (3), strongly agree (4). The numerical ranking was made, and the averages were compared in statistical analyses (Table 4).

There was no statistically significant difference between the time since graduation and agreement with the expressions from 1 to 8 indicating the benefits of OAR in contributing to the practice of medicine. $(p>0.05)$.

A statistically significant difference was found between the titles of physicians in respect of the statement: To protect against patient complaints $(p=0.045 ; p<0.05)$. In the paired comparisons made to determine the level of significance, general practitioners agreed with the statement at a significantly lower rate than CFMS $(p=0.027)$ and specialist doctors $(p=$ $0.027)$. The agreement rates of family medicine residents were significantly lower than those of CFMS $(p=0.048)$ and specialist doctors $(p=0.041)$. No statistically significant difference was found in other paired comparisons ( $p>0.05$ ).

A statistically significant difference was found between the titles of physicians in respect of the statement: Reduction of unnecessary radiation exposure $(p=0.009 ; p<0.01)$. In the paired comparisons made to determine the level of significance, general practitioners $(p<0.01)$ agreed with this statement at a higher rate than family medicine residents $(p=0.002)$ and specialist doctors $(p=0.003)$. No statistically significant difference was found in other paired comparisons $(p>0.05)$.

There was no statistically significant difference between the titles of physicians in respect of agreement with the other expressions $(p>0.05)$.

A statistically significant difference was found between the workplaces of the physicians in respect of the expression: $R e-$ duction of unnecessary radiation exposure $(p=0.014 ; p<0.05)$. In the paired comparisons made to determine the level of significance, physicians working in family health centres and community health centres agreed with the statement at a higher rate than those employed in Teaching Hospitals (University Hospital or Training and Research Hospital) ( $p=0.001 ; p<0.001)$. No statistically significant difference was found in other paired comparisons $(p>0.05)$.

No statistically significant difference was determined between the workplace of physicians in respect of agreement with the other expressions $(p>0.05)$.

\section{Discussion}

This survey was designed to investigate the knowledge, attitudes and behaviour of family physicians about OAR. The study participants comprised family medicine residents, family medicine specialists and faculty members, CFMS and general practitioners involved in family medicine practice. The majority of the participants were family medicine residents, and nearly $60 \%$ of the data was collected from Teaching Hospitals (Research \& Training Hospitals and University Hospitals). This was followed by family physicians working in family health centres and community health centres $(36 \%)$ and family medicine specialists working in State hospitals (6.6\%). The results of this study may not reflect the entire population of family physicians, as the distribution within the subgroups was not regular. Since the vast majority of the participants were residents, the median age of the physicians was 30 years. This skewed distribution may have been caused by the delivery of the questionnaire online and that young physicians are more familiar with Internet technology than older physicians [29].

Of the total respondents to the survey, 89 physicians stated that they were aware of OAR, $49(10.7 \%)$ responded positively to all items of the rules when they were presented one by one, although they did not know that the survey was related to OAR. This suggests that only $10.7 \%(n=49)$ of the physicians knew and used OAR for appropriate purposes, although $43.5 \%$ ( $n=$ 160) of 367 physicians unaware of OAR stated that they would request an X-ray for all the given clinical conditions, which means that they applied the rules without knowing them as the "Ottawa Ankle Rules".

Research in literature on the awareness of OAR has been mostly related to emergency physicians. Previous studies in Turkey are related to measuring the sensitivity and specificity of the rules $[15,30,31]$. In a study by Brehaut et al. in Canada, $99.2 \%$ of emergency physicians reported awareness of OAR [6]. Graham et al. conducted a study about the awareness of OAR of emergency physicians in five countries (USA, Canada, France, UK, Spain) and Spanish physicians constituted the group of physicians with the lowest awareness (21\%). OAR awareness reached $99 \%$ in the Canadian emergency physician group, 96\% in the US, $91 \%$ in the UK and $69 \%$ in France. The reason for the higher awareness of OAR in English-speaking countries was said to be because the literature on OAR has been mostly published in English indexes [26].

In the current study, 59\% of the participants stated that an $X$-ray should be requested when there was bone tenderness on the basis of the $5^{\text {th }}$ metatarsal, and $55.9 \%$ when there was bone tenderness on the navicular. These percentages have been reported as $90 \%$ and $80 \%$, respectively, in literature [6]. Of the current study respondents, $93 \%$ stated that "Inability to bear weight both immediately after injury and in the emergency de- 
partment" is an indication for X-ray, which has been widely accepted $(75-90 \%)$ by participants in other studies in literature. The inability to bear weight immediately after trauma has always been accepted as a historical and conventional attitude of physicians for sending a patient for an X-ray, and this attitude has been shown in other studies in literature $[6,10]$.

At the end of the current study questionnaire, the participants were asked about the benefits of OAR in contributing to the practice of medicine. The vast majority of physicians (>90\%) agreed that the benefits of OAR were: Reducing the cost of healthcare, Appropriateness to evidence-based medicine, Clarification of X-ray requirement, Reduction of unnecessary radiation exposure and Ease of application. The rates of agreement with other statements were: To protect against malpractice $-74.8 \%$; To protect against patient complaints - $66.9 \%$; Clarification of referral criteria - $85.7 \%$. These percentages demonstrate that physicians lean towards OAR and think that it is useful to practice the rules, which is consistent with the findings of other studies $[10-12,24,26]$. With the aim of increasing the awareness of the rules during the learning process, it can be recommended that OAR are included in training programs in the internships of orthopaedics and traumatology, as well as emergency medicine as a part of undergraduate clinical medical education [32]. OAR should also be undertaken in postgraduate education as a part of the family medicine residency curriculum, since family medicine residents and specialists frequently treat ankle/foot trauma patients in the emergency departments of Teaching Hospitals and Integrated State Hospitals.

CFMS and family medicine specialists working in the field agreed at a higher rate than the residents that OAR may protect against patient complaints. This result can be interpreted as reasonable, since the legal responsibilities of the residents are relatively low [33] and they face fewer complaints and malpractice suits, as they are protected by their institutions. Residents are still considered as students, and with the benefit of being in a Teaching Hospital, can consult other physicians and disciplines. This benefit is lost when working alone as a primary care physician in the community.
General practitioners agreed at a higher rate than residents and specialists with the statement of Reduction of unnecessary radiation exposure as a benefit for medical practice. The agreement rate of physicians working in family and community health centres with Reduction of unnecessary radiation exposure was higher than that of physicians working in Teaching Hospitals. The reason for this could be because it is impossible or difficult to reach imaging modalities while working in family and community health centres in Turkey. Family medicine residents and specialists who work in Teaching Hospitals and State Hospitals have greater access to imaging technologies, which enables them to make more requests for radiographic examination. Therefore, increasing the availability of imaging technologies increases the radiation exposure risk for patients due to the frequency of demands, as well as elevating the perception of the process as a norm. OAR has been shown to have extremely high sensitivity for prediction of a fracture, and the adoption of the rules by physicians leads to reduced use of ankle radiography [24].

\section{Limitations of the study}

Although this is the first study on awareness of OAR in Turkey, it has the limitations of self-administered surveys. There was also a lack of representation of subgroups of family physicians as the study was based on voluntary participation. The distribution of respondents was skewed resulting in limited representation of all family physician subgroups.

\section{Conclusions}

The results of this study demonstrated limited awareness and practice of OAR among primary care physicians in Turkey. As the healthcare system requires primary care physicians to deal with traumatic ankle/foot injuries, there should be a greater awareness of the OAR, with information and training given to all primary care physicians.

Source of funding: This work was funded from the authors' own resources. Conflict of interests: The authors have no conflict of interests to declare.

\section{References}

1. Laupacis A, Sekar N. Clinical prediction rules: a review and suggested modifications of methodological standards. JAMA 1997; 277(6): 488-494.

2. Wasson JH, Sox HC, Neff RK, et al. Clinical prediction rules: applications and methodological standards. N Engl J Med 1985; 313(13): 793-799.

3. Selskyy P, Vakulenko D, Televiak A, et al. On an algorithm for decision-making for the optimization of disease prediction at the primary health care level using neural network clustering. Fam Med Prim Care Rev 2018; 20(2): 171-175.

4. Patel VL, Arocha JF, Diermeier M, et al. Methods of cognitive analysis to support the design and evaluation of biomedical systems: the case of clinical practice guidelines. J Biomed Inform 2001; 34(1): 52-66.

5. Adams AS, Soumerai SB, Lomas J, et al. Evidence of self-report bias in assessing adherence to guidelines. Int J Qual in Health Care 1999; 11(3): 187-192.

6. Brehaut JC, Stiell IG, Visentin L, et al. Clinical decision rules "in the real world": how a widely disseminated rule is used in everyday practice. Acad Emerg Med 2005; 12(10): 948-956.

7. Garfield FB, Garfield JM. Clinical judgment and clinical practice guidelines. Int J Technol Assess Health Care 2000; 16(4): 1050-1060.

8. Pijnenburg A, Glas AS, de Roos MA, et al. Radiography in acute ankle injuries: the Ottawa Ankle Rules versus local diagnostic decision rules. Ann Emerg Med 2002; 39(6): 599-604.

9. Eggli S, Sclabas GM, Eggli S, et al. The Bernese ankle rules: a fast, reliable test after low-energy, supination-type malleolar and midfoot trauma. J Trauma Acute Care Surg 2005; 59(5): 1268-1271.

10. Stiell IG, Greenberg GH, McKnight RD, et al. A study to develop clinical decision rules for the use of radiography in acute ankle injuries. Ann Emerg Med 1992; 21(4): 384-390.

11. Stiell I, McDowell I, Nair R, et al. Use of radiography in acute ankle injuries: physicians' attitudes and practice. CMAJ 1992; 147(11): 1671-1678.

12. Stiell I, Wells G, Laupacis A, et al. Multicentre trial to introduce the Ottawa ankle rules for use of radiography in acute ankle injuries. BMJ 1995; 311(7005): 594-597.

13. Smith GF, Madlon-Kay DJ, Hunt V. Clinical evaluation of ankle inversion injuries in family practice offices. J Fam Pract 1993; 37(4): 345-349.

14. Bachmann LM, Kolb E, Koller MT, et al. Accuracy of Ottawa ankle rules to exclude fractures of the ankle and mid-foot: systematic review. BMJ 2003; 326(7386): 417, doi: 10.1136/bmj.326.7386.417. 
15. Yavuz U, Sökücü $\mathrm{S}$, Demir $\mathrm{B}$, et al. Ayak bileği travmalı hastalarda rutin grafi gerekliliğinin Ottawa kuralları ile değerlendirilmesi. GOZTEPETRH 2013; 28(4): 204-208 (in Turkish).

16. Jonckheer $\mathrm{P}$, Willems $\mathrm{T}$, De Ridder $\mathrm{R}$, et al. Evaluating fracture risk in acute ankle sprains: any news since the Ottawa ankle rules? A systematic review. Eur J Gen Pract 2016; 22(1): 31-41.

17. Gerard WA, Staffer A, Bullock K, et al. Family physicians in emergency medicine: new opportunities and critical challenges. Ann Fam Med 2010; 8(6): 564-565.

18. Stother I. Incidence of minor fractures in twisting injuries of the ankle. Injury 1974; 5(3): 213-214.

19. Diehr P, Highley R, Dehkordi F, et al. Prediction of fracture in patients with acute musculoskeletal ankle trauma. Med Decis Mak 1988; 8(1): 40-47.

20. Lloyd S. Selective radiographic assessment of acute ankle injuries in the emergency department: barriers to implementation. CMAJ 1986; 135(9): 973-974.

21. Yazdani S, Jahandideh H, Ghofrani H. Validation of the Ottawa Ankle Rules in Iran: a prospective survey. BMC Emerg Med 2006; 6(1): 3, doi: 10.1186/1471-227X-6-3

22. Chorley JN, Hergenroeder AC. Management of ankle sprains. Pediatr Ann 1997; 26(1): 56-64.

23. Paige NM, Nouvong A. The top 10 things foot and ankle specialists wish every primary care physician knew. Mayo Clin Proc 2006; 81(6): 818-822.

24. Stiell IG, McKnight RD, Greenberg GH, et al. Implementation of the Ottawa ankle rules. JAMA 1994; 271(11): 827-832.

25. Auleley G-R, Ravaud P, Giraudeau B, et al. Implementation of the Ottawa Ankle Rules in France: a multicenter randomized controlled trial. JAMA 1997; 277(24): 1935-1939.

26. Graham ID, Stiell IG, Laupacis A, et al. Awareness and use of the Ottawa ankle and knee rules in 5 countries: can publication alone be enough to change practice? Ann Emerg Med 2001; 37(3): 259-266.

27. Lambers K, Ootes D, Ring D. Incidence of patients with lower extremity injuries presenting to US emergency departments by anatomic region, disease category, and age. Clin Orthop Relat Res 2012; 470(1): 284-290.

28. Saxena A. International advances in foot and ankle surgery. New York: Springer Science \& Business Media; 2011.

29. Lusk C, Delclos GL, Burau K, et al. Mail versus internet surveys: determinants of method of response preferences among health professionals. Eval Health Prof 2007; 30(2): 186-201.

30. Aslan I, Aslan A, Atay T, et al. Ayak Bileği Burkulmalarında Gereksiz Radyografi İstemleri Azaltılabilir mi? Süleyman Demiral Univ Tıp Fak Der 2007; 14(2): 7-10 (in Turkish).

31. Kose $\mathrm{O}$, Gokhan S, Ozhasenekler A, et al. Ayak ve ayak bileği yaralanmalarında Ottawa ayak bileği kuralları ve Bernese ayak bileği kurallarının karşılaştıılması. Turk J Emerg Med 2010; 10(3): 101-105 (in Turkish).

32. Hankemeier DA, Popp JK, Walker SE. Familiarity with and use of clinical prediction rules and patient-rated outcome measures. Athl Train Sports Health Care 2017; 9(3): 108-123.

33. Kesselheim AS, Austad KE. Residents: workers or students in the eyes of the law? N Eng/ J Med 2011; 364(8): $697-699$.

Tables: 4

Figures: 1

References: 33

Received: 25.03.2019

Reviewed: 18.04 .2019

Accepted: 11.05.2019

Address for correspondence:

Hüsna Çevik, MD

Ankara University Medical School

İbni Sina Hospital

Family Medicine Department

Talatpaşa Blvd, No. 82

Altındağ/Ankara

Turkey

Tel.: +90 5547390727

E-mail: saricahusna@gmail.com 